\title{
Utilização de termografia infravermelha para avaliação de fissuras em fachadas com revestimento de argamassa e pintura
}

\author{
Using infrared thermography to evaluate cracks on \\ facades rendered with mortar and painting
}

\section{Juliana Gomes de Freitas Helena Carasek Oswaldo Cascudo}

\section{Resumo}

A

$\mathrm{s}$ fachadas dos edifícios estão expostas aos fenômenos climatológicos da região em que se localizam. A falta de adequada compreensão da interação entre os ciclos de temperatura e de umidade e os revestimentos de fachada favorece sua degradação. Nesse contexto, o monitoramento e o estudo do efeito desses aspectos físicos são importantes para a garantia da durabilidade das fachadas. Em outros países a termografia infravermelha vem sendo utilizada como técnica não destrutiva para a avaliação de problemas nas edificações. Nesse sentido, o presente trabalho tem como objetivo aplicar a termografia na avaliação de manifestações patológicas relacionadas à temperatura em revestimentos de fachadas. Para tanto, realizaram-se imagens utilizando um termovisor em diferentes horários do dia nas estações seca e chuvosa em uma edificação da cidade de Goiânia, GO. Aferiu-se também a temperatura superficial, em pontos das quatro orientações das fachadas. Por fim, mapearam-se as manifestações patológicas existentes com o auxílio de programa computacional. Como resultado, verificou-se que parte das fissuras levantadas foi visualizada nas imagens térmicas. Verificou-se, também, que o período seco e o horário da tarde provocaram maiores diferenças nas temperaturas superficiais, resultando em isotérmicas mais claras, o que possibilitou a obtenção de imagens que revelaram alguns dos problemas mapeados.

Palavras-chave: Fachada. Revestimento. Temperatura. Termografia infravermelha. Fissura.

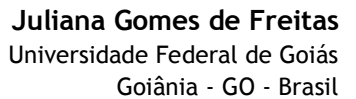

Goiânia - GO - Brasil

Helena Carasek

Universidade Federal de Goiás Goiânia - GO - Brasil

Oswaldo Cascudo Universidade Federal de Goiás Goiânia - GO - Brasil

Recebido em 20/01/13

Aceito em 14/12/13

\begin{abstract}
Building facades are exposed to the climatic phenomena of the region where they are located. The lack of adequate understanding of the interaction between temperature and humidity and the facade renderings contributes to their degradation. In this context, the monitoring and the study of the effects of these physical aspects are desirable in order to guarantee the durability of the facades. In other countries, infrared thermography is being used as a nondestructive technique to evaluate problems in buildings. This study focuses on the application of thermography in the evaluation of pathologies related to temperature in facade renderings of buildings in the city of Goiania, Brazil. In order to do that, thermal images were made using a thermal camera at different times of the day in the dry season and in the rainy season. In addition, the surface temperature in parts of the facades in the four directions was measured. Finally, the degradation of the facades was mapped with the aid of a computer program. The results demonstrated that some of the cracks mapped were shown in the thermal images. Also, significant differences in surface temperature were observed during the dry season and in the afternoon, resulting in clearer isothermals, making it possible to obtain images that revealed some of the problems mapped.
\end{abstract}

Keywords: Facade. Rendering. Temperature. Infrared thermography. Cracks.

FREITAS, J. G. DE; CARASEK, H.; CASCUDO, O. Utilização de termografia infravermelha para avaliação de fissuras em 57 fachadas com revestimento de argamassa e pintura. Ambiente Construído, Porto Alegre, v. 14, n. 1, p. 57-73, jan./mar. 2014.

ISSN 1678-8621 Associação Nacional de Tecnologia do Ambiente Construído. 


\section{Introdução}

A durabilidade dos revestimentos de fachada está relacionada a sua interação com fenômenos climáticos. Chuva, vento, insolação e material particulado em suspensão no ar são exemplos de elementos da natureza e do processo de urbanização que, por sua agressividade, colocam os edifícios em situações desfavoráveis, reduzindo a vida útil das construções, em virtude da falta de compreensão sistêmica desses fatores no ato de projetar.

As manifestações patológicas em fachadas resultantes da influência dos fenômenos atmosféricos vão desde um comprometimento estético sem maiores riscos, passando por fissuras, infiltrações e manchamentos mais acentuados, chegando até aos casos mais críticos de descolamentos e desplacamentos dos revestimentos. Nesse contexto, entende-se que o monitoramento da temperatura é essencial para se produzirem subsídios que retroalimentem novos projetos e a especificação de materiais voltados ao correto desempenho dos revestimentos, garantindo, assim, a durabilidade requerida para os edifícios, o conforto e a satisfação dos usuários.

Os ensaios destrutivos aplicados em materiais, componentes ou sistemas construtivos tornam-se indesejáveis quando se trata de diagnóstico de problemas no contexto das edificações em uso. Com efeito, o desenvolvimento de técnicas não destrutivas que visem ao diagnóstico de deteriorações nas construções, de forma geral, vem sendo objeto de estudo de muitas pesquisas.

Entre essas técnicas, pode-se destacar a termografia infravermelha, que produz uma imagem térmica, em que cada cor representa um nível de temperatura superficial dos objetos. Por meio da análise da figura obtida pelo equipamento, é possível identificar a existência de focos de umidade, anomalias, elementos ocultos, entre outros (GRINZATO et al., 2011).

Segundo Cortizo, Barbosa e Souza (2011), apesar de a técnica ser bastante difundida nos países europeus, graças ao grande acervo histórico, no Brasil sua utilização é relativamente nova, seja pelo alto custo dos equipamentos de análise, seja por sua dificuldade de aplicação prática.

Nesse sentido, o presente trabalho visa verificar a aplicabilidade da termografia infravermelha na avaliação de fissuras relacionadas à temperatura em revestimento de argamassa de fachadas, aspecto ainda pouco explorado com a técnica em questão.

\section{Revisão da literatura}

A termografia infravermelha é uma técnica não destrutiva de imagens de sensoriamento remoto que vem sendo utilizada para detectar falhas em equipamentos elétricos, bem como alterações em diferentes partes do edifício, como a cobertura, os sistemas estruturais, os sistemas de vedação em alvenaria e os revestimentos. Uma dessas alterações refere-se à detecção de excessos de umidade e temperatura, altamente responsáveis por danos nos materiais, com reflexos na saúde dos usuários (LIMA; MAGNANI; NUNES, 2006; CORTIZO, 2007; LERMA; CABRELLES; PORTALÉS, 2011).

Apesar da escassez de literatura relacionada à termografia no Brasil, vários são os estudos internacionais encontrados que possuem razoável amplitude de finalidades no campo dos materiais de construção. No entanto, certa ênfase é dada ao comportamento dos revestimentos de fachadas e dos monumentos históricos (MOROPOULOU; AVDELIDIS; KOUI, 2000; BARREIRA; FREITAS, 2005; BARREIRA; FREITAS, 2007; ALBATICI; TONELLI, 2010; LERMA; CABRELLES; PORTALÉS, 2011; CERDEIRA et al., 2011).

Lerma, Cabrelles e Portalés (2011) procederam ao monitoramento e a ações de conservação de um edifício histórico localizado na região de Leuven, na Bélgica. Por meio de um mapeamento qualitativo, conseguiram localizar a distribuição de umidade nas fachadas. As imagens foram captadas em quatro horários diferentes durante $24 \mathrm{~h}$. A análise das imagens possibilitou aos autores constatar que:

(a) massas úmidas eram mais frias pela manhã em comparação às massas secas;

(b) durante o dia, as massas úmidas aumentaram sua temperatura mais devagar que as massas secas;

(c) durante a noite, massas úmidas se resfriaram mais lentamente que as massas secas.

Barreira e Freitas (2007) realizaram pesquisa experimental na qual blocos de concreto celular autoclavado foram parcialmente imersos em água. Eles concluíram que, durante o período de absorção das amostras, o nível de água foi visualmente observado e termograficamente detectado por sua variação superficial de temperatura. A temperatura variou devido à evaporação superficial, que, sendo uma reação endotérmica, induziu ao resfriamento local. 
O período de secagem começou imediatamente após as amostras terem sido removidas da água. Após $40 \mathrm{~h}$, os termogramas ainda demonstraram diferenças significativas de temperatura. Contudo, na medida em que a secagem progredia, as áreas mais frias diminuíam, e as isotérmicas aumentavam. Esse processo revelou que a secagem ocorreu mais rapidamente nas bordas superiores e laterais da amostra. Ao final do teste, a temperatura superficial se tornou quase uniforme, e, portanto, a distribuição da umidade não era mais perceptível.

O fenômeno da condensação superficial nos revestimentos também pode ser detectado pela termografia. Nesse sentido, Barreira e Freitas (2005) obtiveram termogramas em diferentes orientações de fachadas em pontos com e sem problemas de manchas, demonstrando variações de temperatura superficial. Áreas com microorganismos possuíam maiores variações de temperatura superficial. Por outro lado, áreas sem problemas visíveis indicaram temperaturas superficiais mais uniformes. Barreira e Freitas (2005) também localizaram alguns defeitos causados por impactos mecânicos ou regiões de separação de materiais.

Cerdeira et al. (2011) utilizaram modelos experimentais formados por painéis com peças de granito com $2 \mathrm{~cm}$ e $3 \mathrm{~cm}$ de espessura estruturados em paredes compostas de blocos cerâmicos revestidas com argamassa de cimento. Em ambos os modelos, produziram-se defeitos sobre a argamassa com o intuito de se verificar se eram detectáveis pela técnica da termografia infravermelha. Os referidos defeitos consistiram em porções do revestimento de argamassa retirados com formatos circulares e retangulares, simulando descolamentos. Os testes foram conduzidos em laboratório. Utilizou-se um aquecedor para obter gradiente de temperatura de 4 ${ }^{\circ} \mathrm{C}$ a $30^{\circ} \mathrm{C}$.

Como resultado, a termografia possibilitou a identificação dos defeitos sob os painéis com as duas espessuras $(2 \mathrm{~cm}$ e $3 \mathrm{~cm}$ ). Contudo, o defeito circular com $3 \mathrm{~cm}$ de diâmetro, o menor deles, não foi verificado sob o painel de granito de $3 \mathrm{~cm}$ de espessura. Esse fato pode gerar uma ideia do menor tamanho de defeito detectável pela técnica. Outra constatação foi visualizada nos experimentos que utilizaram o aquecimento. As áreas com defeitos possuíam temperatura inferior em relação às regiões de seu entorno. Ficou demonstrado que a transferência de calor por condução pela parede é diferente se o local possui ou não algum tipo de vazio. Em partes do revestimento de argamassa sem defeitos não foi constatada variação de temperatura. Já em locais com vazios, observou-se variação de temperatura de $1{ }^{\circ} \mathrm{C}$.

Albatici e Tonelli (2010) realizaram pesquisa baseada em métodos experimentais e levantamentos de campo objetivando resultados quantitativos por meio da termografia infravermelha. Os autores acreditavam que as medições poderiam gerar valores mais reais de transmitância que os teóricos. Estes últimos são calculados por meio de valores tabelados de emissividade e de condutividade térmica contidos na NBR 15220-2 (ABNT, 2005). Os autores chegaram a resultados até $100 \%$ maiores de transmitância que os valores teóricos. Além disso, verificaram que, para a pesquisa em questão, o melhor horário para realização das medições com a termografia era à noite, quando ocorre a maior diferença de temperatura entre o interior e o exterior da edificação, uma vez que se estocou o máximo de calor após a ocorrência de insolação durante todo o dia. Indicam, também, condições de vento menor que $1 \mathrm{~m} / \mathrm{s}$ para evitar trocas de calor por convecção.

Moropoulou, Avdelidis e Koui (2000) realizaram pesquisa em laboratório na qual utilizaram protótipos de alvenaria revestida com diferentes tipos de argamassa (com e sem cal) e placas de pedra. Os autores realizaram testes em que foram verificadas a absorção de água capilar e a taxa de evaporação, o que possibilitou a interpretação dos termogramas em laboratório. Desse experimento, em geral, verificou-se que amostras que apresentam altas percentagens de absorção de água apresentam reduções consideráveis de temperatura, enquanto amostras com baixas percentagens de absorção de água oferecem pequenas diferenças de temperatura.

A ASTM C 1060-11a (AMERICAN..., 2011) estabelece recomendações referentes às condições ambientais em que se devem realizar medições com termografia infravermelha em edificações típicas encontradas nos Estados Unidos: steel frame ou wood frame. Essas condições são as seguintes: diferença mínima de temperatura de 10 ${ }^{\circ} \mathrm{C}$ entre as superfícies interna e externa por pelo menos $4 \mathrm{~h}$ antes da medição; não deve haver insolação direta por $3 \mathrm{~h}$ antes da inspeção; e a velocidade do vento deve ser menor do que $6,7 \mathrm{~m} / \mathrm{s}$. A norma também considera que o inspetor deve possuir conhecimento prévio sobre o sistema de imageamento térmico infravermelho, sobre os materiais de construção e sobre os mecanismos de transferência de calor e umidade. Contudo, um profissional com os conhecimentos supracitados pode interpretar os dados obtidos mesmo que não seja possível a realização das medições nas condições mais adequadas. 
Para Mendonça (2005), medições em estruturas ou superfícies de concreto podem ser realizadas durante o dia ou à noite. Se a inspeção for realizada à noite, a maior parte das anomalias no concreto produzirá superfícies cujas temperaturas terão valores entre $0,01{ }^{\circ} \mathrm{C}$ e $5{ }^{\circ} \mathrm{C}$ abaixo da temperatura das superfícies sãs envolventes. Uma inspeção diurna irá reverter os resultados, ou seja, as superfícies correspondentes às anomalias estarão mais quentes do que as superfícies correspondentes sem defeitos. O referido autor se reporta às anomalias como problemas patológicos no concreto decorrentes da corrosão das armaduras ou decorrentes de falhas de adensamento (ninhos de concretagem), além dos problemas gerais associados à infiltração de água.

Desta revisão apresentada, tem-se uma noção da aplicabilidade da termografia no contexto da avaliação de edificações e das pesquisas em materiais e componentes de construção, bem como de sua potencialidade como instrumento auxiliar em termos da análise e diagnóstico de problemas em edifícios e obras de arte.

\section{Objetivos}

O objetivo geral do presente trabalho é aplicar a termografia infravermelha na avaliação de fissuras relacionadas à temperatura em revestimentos de fachadas, bem como identificar o horário do dia e o período do ano mais adequados para as inspeções com o termovisor. Espera-se também, de modo específico, encontrar relação entre as imagens termográficas e os mapeamentos das fissuras e medições de temperatura nas superfícies das fachadas de um edifício público com dois pavimentos na cidade de Goiânia, GO.

\section{Metodologia}

Para o presente estudo, foram selecionados os Blocos A e B das Escolas de Engenharia da Universidade Federal de Goiás (UFG), vistos nas Figuras 1 e 2. A escolha aconteceu pelas características dos blocos, que são semelhantes, pelos detalhes arquitetônicos, que são específicos e se repetem ao longo das fachadas, pela detecção de manifestações patológicas relacionadas aos ciclos de temperatura (fissuração) e pela facilidade de acesso nos vários horários do dia, o que não ocorreria em uma edificação privada.

A construção dos Blocos A e B das Escolas de Engenharia ocorreu em 1961, tendo sofrido duas reformas, uma em 1985 e outra em 2005. Ambas não contaram com grandes intervenções físicas, somente pinturas e instalação de equipamentos (arcondicionado e elevador). O sistema construtivo utilizado emprega estrutura em concreto armado moldado in loco, alvenaria de vedação em bloco cerâmico, revestimento de argamassa e acabamento decorativo em pintura acrílica texturizada. No que tange às dimensões e aos elementos construtivos, como esquadrias, elementos de proteção solar e estéticos, entre outros, ambos os blocos possuem características semelhantes. As dimensões em planta dos Blocos A e B são, respectivamente, $66,60 \mathrm{~m}$ x 8,75 m e $70,80 \mathrm{~m}$ x $8,75 \mathrm{~m}$.

Figura 1 - Localização dos edifícios das Escolas de Engenharia da Universidade Federal de Goiás, no Setor Leste Universitário, em Goiânia, GO

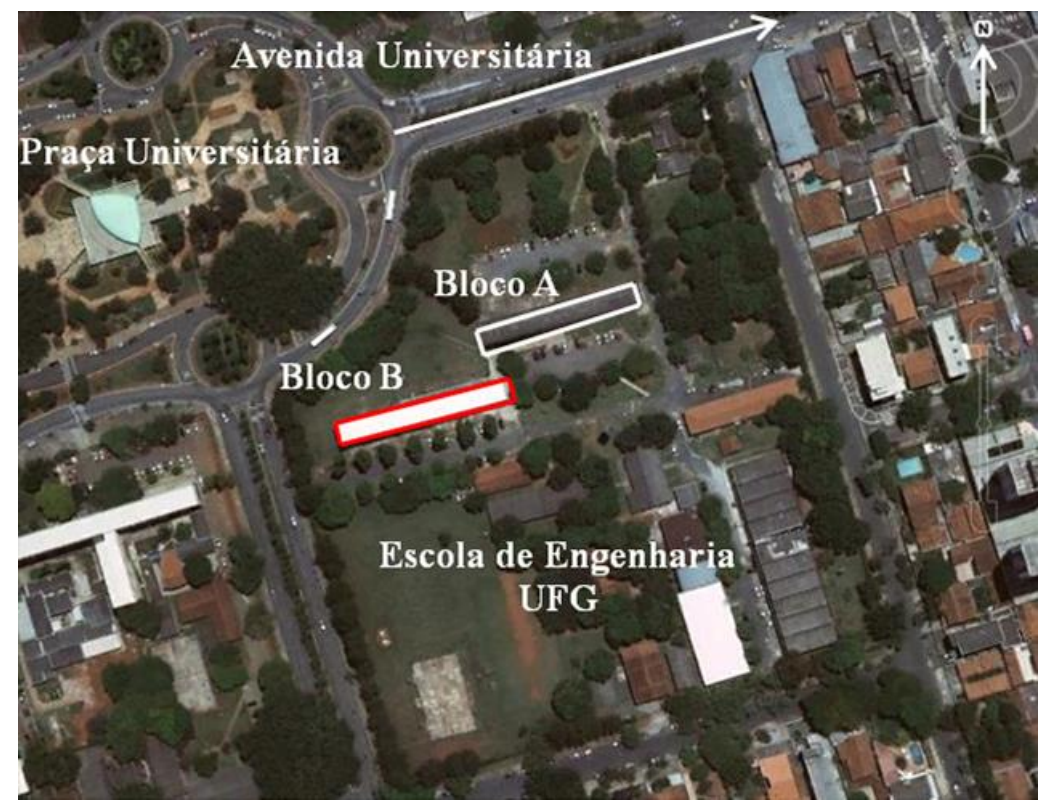

60 Freitas, J. G. de; Carasek, H.; Cascudo, O. 
Figura 2 - (a) Bloco A e (b) Bloco B das Escolas de Engenharia da UFG

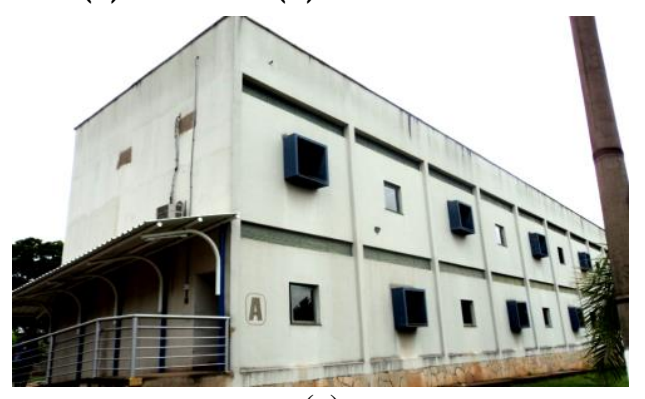

(a)

A metodologia da presente pesquisa estruturou o trabalho em três etapas. Na primeira, realizou-se uma inspeção dos paramentos externos, calcada em análise visual, a fim de quantificar as manifestações patológicas existentes ${ }^{1}$. A segunda refere-se a medições de temperatura superficial em alguns pontos das fachadas dos edifícios. $\mathrm{Na}$ terceira etapa, procedeu-se à obtenção de imagens termográficas das fachadas.

\section{Etapa de inspeção contendo um mapeamento das fissuras incidentes nas fachadas}

A fim de quantificar as fissuras existentes, realizou-se uma inspeção nos paramentos externos dos Blocos A e B das Escolas de Engenharia da UFG, que foi baseada na metodologia utilizada por Antunes (2010), do Laboratório de Ensaio de Materiais da UnB. Para tanto, empregaram-se procedimentos de análise visual, apoiados no uso de máquina fotográfica com resolução conveniente.

Devido à horizontalidade das edificações e à dificuldade de se obterem fotografias completas das fachadas norte ${ }^{2}$ e sul dos dois blocos sem distorções importantes e sem interferências de obstáculos, como a vegetação e veículos do estacionamento, as vistas foram divididas. Utilizaram-se como referência para a divisão os elementos estruturais das fachadas. Para cada bloco foram necessárias 16 áreas por fachada (norte e sul), conforme exemplificado na Figura 3, resultando em 64 fotografias para essas fachadas (para a totalidade dos dois blocos -16 vezes 4

\footnotetext{
${ }^{1}$ A pesquisa como um todo (FREITAS, 2012) envolveu o mapeamento das manifestações patológicas existentes nos edifícios, quais sejam: manchas de sujidade, fantômes e fissuras. Contudo, este artigo aborda exclusivamente as manifestações de fissuras, tendo em vista sua relação direta com os ciclos de temperatura ocasionados pela insolação.

${ }^{2}$ Para facilitar a descrição das orientações das fachadas, a partir deste momento elas serão denominadas apenas norte, sul, leste e oeste, apesar de, na realidade, haver uma distorção de $15^{\circ}$. A título de esclarecimento, a fachada norte tem azimute $105^{\circ}$.
}

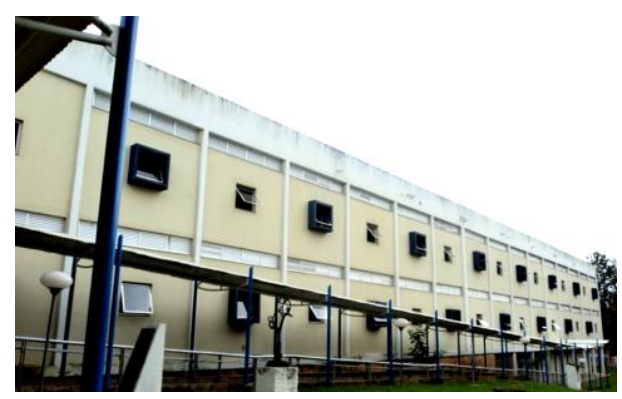

(b)

fachadas). Para as fachadas leste e oeste dos dois edifícios, que possuem pequena extensão, não foi necessária essa subdivisão, sendo feitas 4 fotografias no total (2 fotos para cada edifício, sendo uma para a fachada leste e outra para a fachada oeste, totalizando assim 4 fotografias para os dois blocos). Ao todo, foram produzidas 68 fotografias das fachadas dos dois edifícios.

A distância para a obtenção das imagens foi fixada em $10 \mathrm{~m}$, alterando-se para $5 \mathrm{~m}$ quando eventualmente obstáculos impediam esse padrão.

O levantamento fotográfico buscou oferecer suporte e esclarecer possíveis dúvidas durante a análise e interpretação dos mapeamentos. Os danos visíveis foram registrados em croquis, com os esquemas das áreas (no caso das manchas de sujidade e fantômes) ou comprimentos (no caso das fissuras) em questão desenhados a mão no local, onde se anotavam os problemas detectados por meio de siglas. Depois, realizaram-se os mapeamentos das manifestações patológicas das fachadas com o auxílio de programa de desenho gráfico sobrepondo as fotografias, observando-se também os croquis feitos in loco, como ilustrado na Figura 4.

As fissuras observadas foram delineadas, permitindo a quantificação de sua extensão. Foi também determinado o índice de fissuração, o qual foi calculado pela relação comprimento total das fissuras/área de fachada $\left(\mathrm{m} / \mathrm{m}^{2}\right)$, excluindo-se a área das esquadrias da área da fachada.

\section{Medição de temperatura superficial em fachadas}

As medições de temperatura superficial foram realizadas em vários pontos da superfície do revestimento das quatro fachadas dos edifícios em estudo, a saber: sobre detalhes arquitetônicos de proteção das janelas, sobre a estrutura e sobre a alvenaria, conforme destaca a Figura 5. Essas medidas aconteceram no período seco em Goiânia, durante o mês de setembro de 2011, e no período chuvoso, no mês de janeiro de 2012 . 
Figura 3 - Exemplo da subdivisão das fachadas em áreas do Bloco A para a obtenção das fotografias

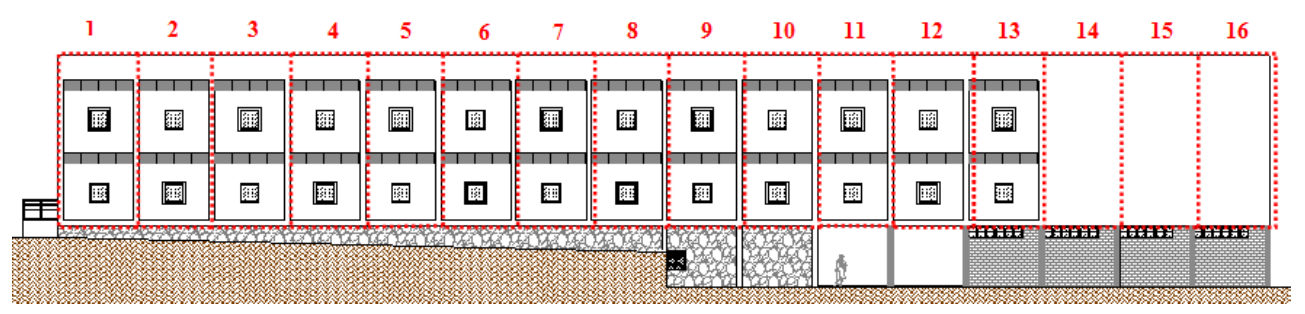

Figura 4 - Exemplo da confecção dos mapeamentos das manifestações patológicas da fachada sul do Bloco A

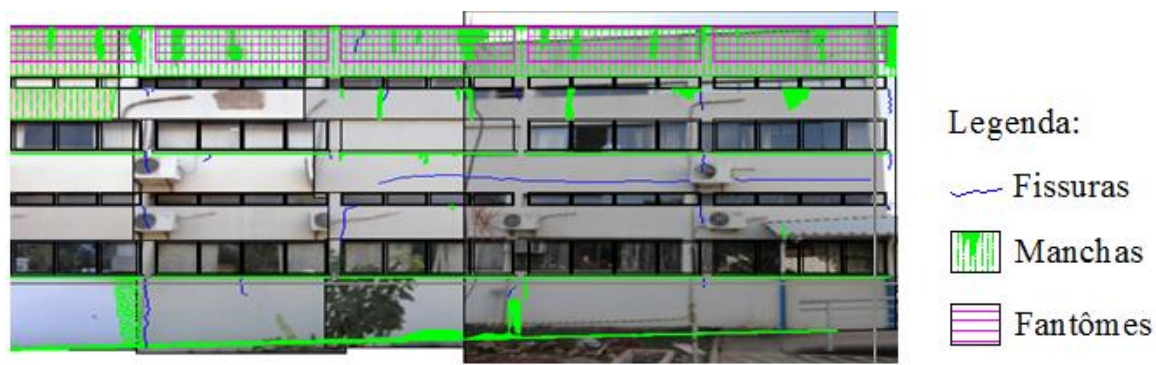

Figura 5 - Exemplo da localização da nomenclatura utilizada para fazer referência aos pontos onde foram realizadas as medições de temperatura superficial

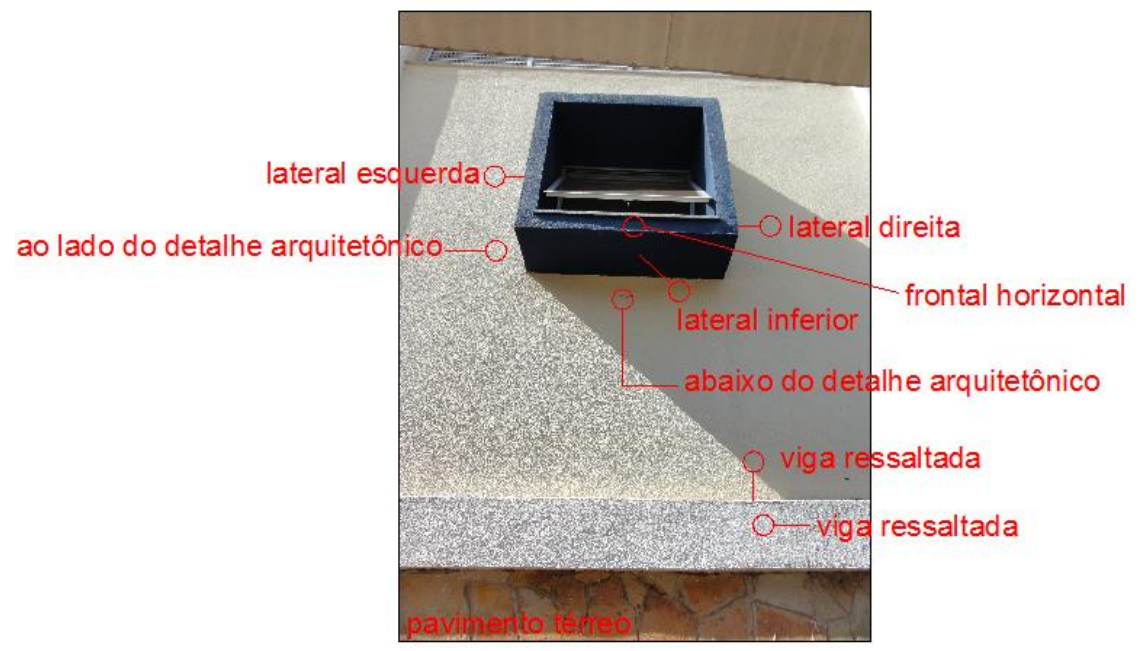

O equipamento utilizado foi um termômetro digital infravermelho (sem contato) modelo InfraTerm, fabricado pela IncoTerm. A duração da coleta foi de 2 meses, ocorrendo medições durante 5 dias aleatórios em cada período climático. Durante tais dias foram realizadas medições em três horários: às $8 \mathrm{~h}, 15 \mathrm{~h}$ e $21 \mathrm{~h}$. Esses horários foram definidos de maneira a serem viáveis e sensíveis à amplitude térmica diária. No total, foram 1.770 dados coletados de temperatura superficial das fachadas.

Os locais das coletas foram definidos após a realização da inspeção nas fachadas, nas regiões que se encontravam mais deterioradas e que melhor representaram as manifestações patológicas levantadas. Tais locais foram adaptados da metodologia de Gaspar e Brito (2005).

\section{Termografia infravermelha}

A termografia infravermelha foi utilizada para caracterizar o comportamento higrotérmico das fachadas dos edifícios do presente estudo. A captura das imagens foi conduzida seguindo-se os mesmos procedimentos gerais e critérios adotados para as fotografias por ocasião da inspeção nas fachadas. Contudo, foi necessário subdividir as áreas descritas em três (verticalmente), resultando, assim, em 48 imagens para cada fachada norte e sul dos blocos (16 vezes 3 ). O distanciamento padronizado de $10 \mathrm{~m}$ foi mantido. 
As imagens foram capturadas em 2 dias, sendo um durante o período seco, e outro no chuvoso. Assim como para as medições de temperatura, escolheram-se horários para sua viabilidade e sensibilidade quanto à amplitude térmica diária, quais sejam: $8 \mathrm{~h}, 15 \mathrm{~h}$ e $21 \mathrm{~h}$. No total, foram captadas 416 imagens térmicas.

Para os fins da presente etapa do trabalho, utilizouse uma termocâmera Fluke, modelo Ti10, que possui uma faixa de detecção de temperatura de $20{ }^{\circ} \mathrm{C}$ a $250{ }^{\circ} \mathrm{C}$, com precisão de $\pm 2{ }^{\circ} \mathrm{C}$. O foco desse aparelho é manual, sendo ajustado até que a imagem fique a mais nítida possível. Como se trata de uma câmera que funde a imagem térmica com a digital, a resolução da câmera visual é de 640 x 480 pixels. Quanto à emissividade, ajustou-se no aparelho um valor igual a 0,95 , que é condizente a emissividades de superfícies eficientes quanto à irradiação de energia (alta emissividade), como utilizado nos trabalhos de Dactu et al. (2005) e Mario (2011).

\section{Resultados e discussões}

\section{Resultados da inspeção nas fachadas mediante mapeamento das fissuras}

Com base no levantamento fotográfico e sobreposição das imagens aos desenhos das fachadas em programa computacional específico para representação de projetos, obteve-se o mapeamento das manifestações patológicas de cada fachada dos edifícios em estudo. A Figura 6 representa o mapeamento da fachada norte do Bloco A. Observa-se a grande quantidade de fissuras tanto nos detalhes arquitetônicos de proteção das janelas como nos revestimentos sobre estrutura e alvenaria, cujas causas gerais são conhecidas, a saber:

(a) em envoltória de aberturas: ausência ou ineficiência de vergas e/ou contravergas;

(b) na interface da alvenaria e estrutura:

deformações excessivas das vigas e lajes ou deficiência de ancoragem principalmente na região alvenaria/pilar; ligações demasiadamente rígidas na região da fixação da viga e alvenaria ou movimentações higrotérmicas diferenciais entre a alvenaria e a estrutura; e

(c) próximo à laje de cobertura: movimentação térmica.

Tendo em vista que a fachada norte em Goiânia recebe insolação direta (sem nebulosidade) durante o período seco, entre os meses de maio a setembro, durante todo o dia e com ângulo de incidência de $50^{\circ}$, compreende-se a alta variação térmica diária, ocasionando a dilatação e a retração dos elementos construtivos.

Na fachada norte, à direita, observa-se a ocorrência de fissuras a $45^{\circ}$. A priori, essas fissuras inclinadas poderiam ser atribuídas a um recalque diferencial da edificação; no entanto, analisando-se a fachada oeste, na parte contígua à fachada norte, não existem fissuras inclinadas. Dessa forma, não há indícios para caracterização desse tipo de fissuração.

Em relação à fachada sul do Bloco $\mathrm{A}$, verificou-se a presença de fissuras, mas em quantidade bem inferior se comparada à fachada norte, conforme mostra a Figura 7. Ressalta-se que a fachada sul na cidade de Goiânia somente recebe insolação difusa (grande nebulosidade) durante o período chuvoso e com alto ângulo de incidência $\left(83^{\circ}\right)$, não proporcionando grandes aumentos de temperatura durante o dia, como ocorre na orientação norte. Para melhor entendimento em relação à insolação direta e difusa, bem como o ângulo de incidência nas orientações norte e sul durante o período seco e chuvoso em Goiânia, cabe a observação da Figura 8.

Os mapeamentos das manifestações patológicas das fachadas das orientações leste e oeste do Bloco A são representados nas Figuras 9 e 10 respectivamente, nas quais se observam fissuras de separação de alvenaria e estrutura.

Figura 6 - Mapeamento das manifestações patológicas da fachada norte do Bloco A

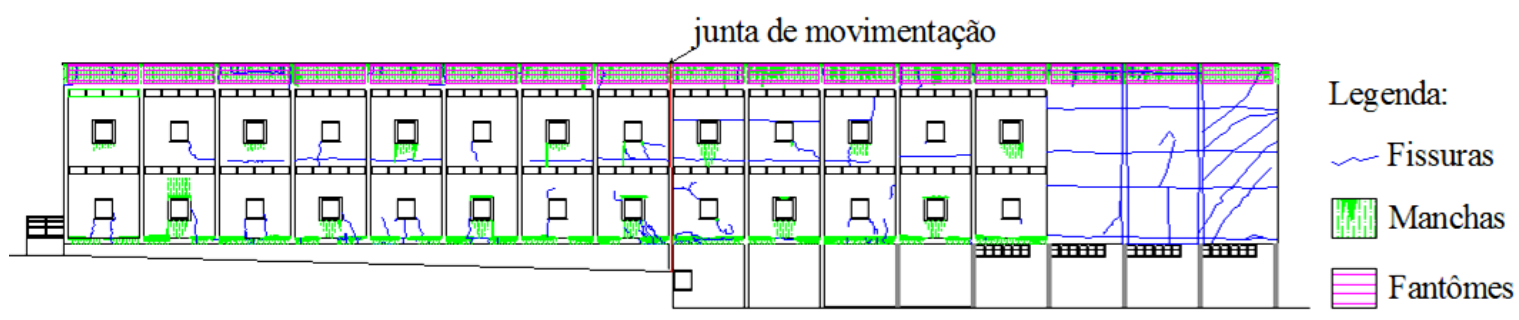


Figura 7 - Mapeamento das manifestações patológicas da fachada sul do Bloco A

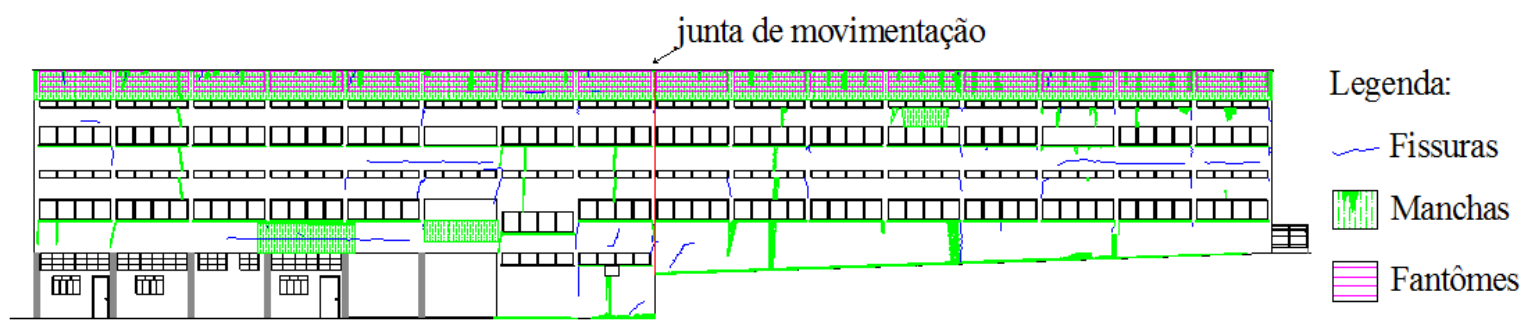

Figura 8 - Incidência solar nas orientações norte e sul durante período seco e chuvoso em Goiânia

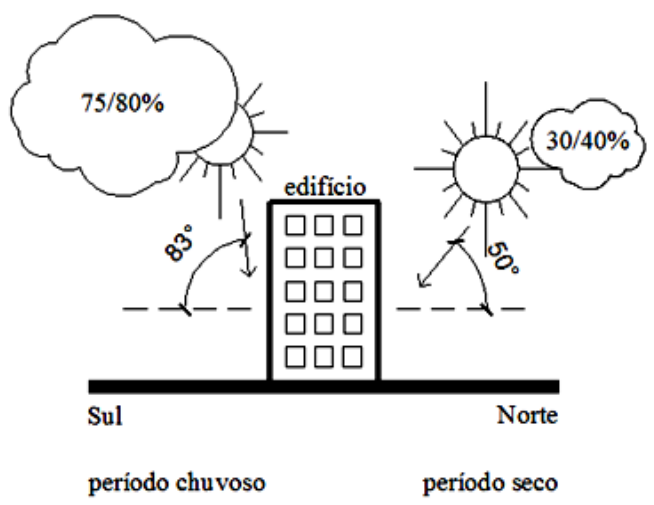

Fonte: adaptado de Fernandes (2007).

Figura 9 - Mapeamento das manifestações patológicas da fachada leste do Bloco A

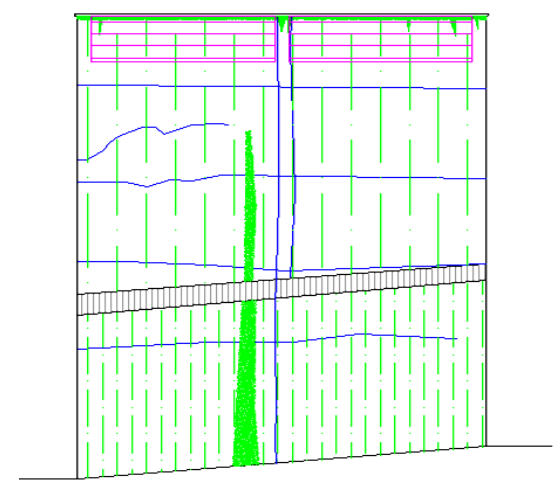

Figura 10 - Mapeamento das manifestações patológicas da fachada oeste do Bloco A

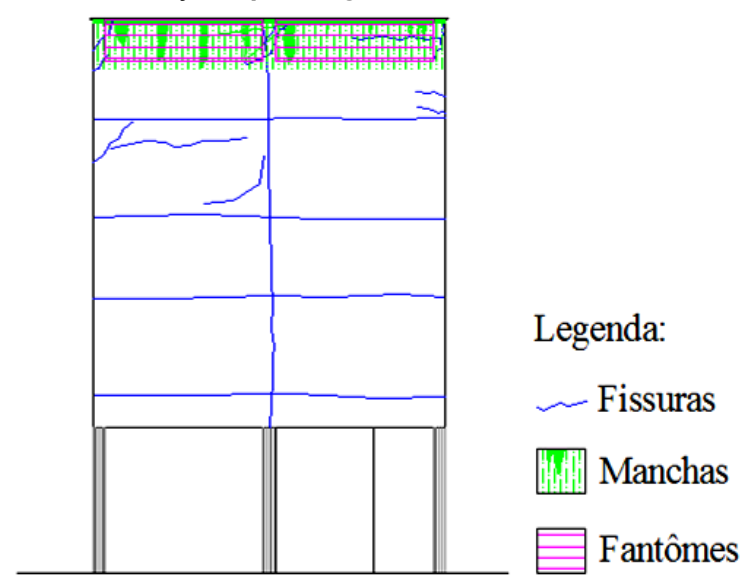

64 Freitas, J. G. de; Carasek, H.; Cascudo, O. 
Os mapeamentos das manifestações patológicas do Bloco B não foram apresentados neste trabalho porque as fissuras têm configuração parecida, no entanto com menor incidência se comparadas ao Bloco A.

A Figura 11 representa o índice de fissuração por área de fachada dos Blocos A e B para cada orientação.

A fachada voltada para oeste do Bloco A foi a que apresentou maior índice de fissuração. Em comparação com a mesma fachada do Bloco B, verificou-se que a primeira não possui vegetação nas proximidades, as quais trazem proteção contra a insolação. Observa-se que as orientações leste e oeste, as quais recebem insolação pela manhã e tarde respectivamente, possuem maiores valores em relação às demais. Contudo, deve-se ressaltar que são "fachadas cegas", possuindo comportamento diferenciado das outras. Relacionando as fachadas norte dos dois blocos, verifica-se que o Bloco A possui maior valor de índice de fissuração. Observando o mapeamento de manifestações patológicas, nota-se que parte dessa fachada no Bloco A (à direita) também é "cega", favorecendo o aparecimento do mesmo tipo de fissuras ocorridas nas orientações leste e oeste dos dois edifícios, elevando o índice no Bloco $\mathrm{A}$; o mesmo não acontece na fachada norte do Bloco B, que possui aberturas em toda a sua extensão (Figura 2). Por esse motivo, calculou-se separadamente o índice de fissuração da fachada Norte do Bloco A para a parte "cega" e para a parte com aberturas, conforme se observa na Figura 12. A região da fachada que não possui aberturas apresentou índice de fissuração de 1,13 $\mathrm{m} / \mathrm{m}^{2}$, enquanto a região com aberturas possui índice de $0,24 \mathrm{~m} / \mathrm{m}^{2}$, índice semelhante ao ocorrido na mesma fachada do Bloco B $\left(0,27 \mathrm{~m} / \mathrm{m}^{2}\right)$. Ressalta-se que o índice de fissuração da parte da fachada com aberturas é $79 \%$ inferior do que a parte "cega" da fachada norte. Os índices de fissuração na fachada sul tendem a apresentar valores menores, uma vez que recebem insolação menor e, consequentemente, variação térmica menos pronunciada entre os elementos que compõem as fachadas.

\section{Medidas da temperatura superficial nas fachadas}

No que tange às medições de temperatura superficial, verificaram-se comportamentos distintos em relação aos períodos de medição (seco e chuvoso), aos horários (8h, 15h e 21h), às orientações das fachadas $(\mathrm{N}, \mathrm{S}, \mathrm{L}$ e $\mathrm{O})$ e às localizações escolhidas (sobre os detalhes arquitetônicos, estrutura e alvenaria).

A título de exemplo ${ }^{3}$, as altas temperaturas atingidas nos detalhes arquitetônicos, principalmente no período seco e às $15 \mathrm{~h}$, são explicadas pela insolação direta (sem nebulosidade) recebida pela fachada norte durante todo o dia nesse período. Outro fato que deve ser ressaltado é a cor desses elementos, que é o azulescuro, o que aumenta a absorção da radiação incidente. $\mathrm{O}$ maior valor médio de temperatura superficial verificado em detalhes arquitetônicos da fachada norte do Bloco B atingiu $50,5{ }^{\circ} \mathrm{C}$, conforme se observa na Figura 13. Contudo, ressalta-se que a temperatura máxima chegou a $65,5{ }^{\circ} \mathrm{C}$ nos valores individuais de medição. Guimarães et al. (2002) mediram temperaturas superficiais na cidade de Goiânia, alcançando 55 ${ }^{\circ} \mathrm{C}$ em regiões do revestimento com pintura escura, valor um pouco menor em relação a medidas individuais obtidas no presente trabalho.

Nos pontos sobre a estrutura, no que tange às orientações de fachada, não houve muita variação, exceto na fachada norte (azimute $105^{\circ}$ ), que recebe insolação quase todo o dia nos dois períodos de medição (seco e chuvoso). Dessa forma, na Figura 14 , observam-se as maiores amplitudes térmicas diárias $\left(22,9{ }^{\circ} \mathrm{C}\right.$ a $\left.45,3{ }^{\circ} \mathrm{C}\right)$ e sazonal $\left(19,4{ }^{\circ} \mathrm{C}\right.$ a $45,3{ }^{\circ} \mathrm{C}$ ), que ocorreram na fachada norte do Bloco A. Compreende-se, então, o alto nível de fissuração $\left(0,43 \mathrm{~m} / \mathrm{m}^{2}\right)$ calculado para essa fachada. Por outro lado, os baixos níveis de temperatura superficial da fachada sul (azimute $285^{\circ}$ ) remetem ao menor índice de fissuração calculado para esta orientação e edifício $(0,15$ $\mathrm{m} / \mathrm{m}^{2}$ ), já que recebe insolação no período seco somente até às $8 \mathrm{~h}$ da manhã.

\section{Resultados das análises por termografia infravermelha}

As imagens termográficas foram obtidas nos três horários de estudo ( $8 \mathrm{~h}, 15 \mathrm{~h}$ e $21 \mathrm{~h}$ ) durante um dia do período seco e outro do chuvoso.

${ }^{3}$ Os resultados completos são encontrados em Freitas (2012). 
Figura 11 - Índice de fissuração das quatro fachadas dos Blocos A e B

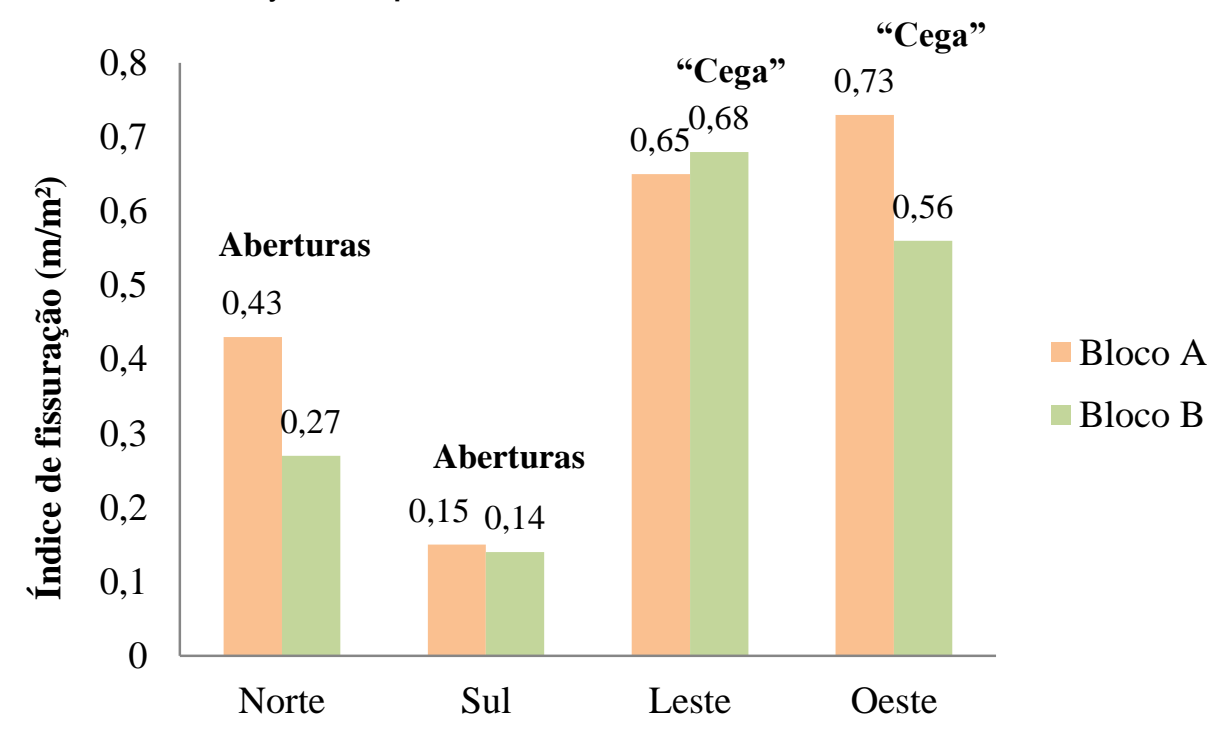

Figura 12 - Índice de fissuração da parte "cega” e da parte com aberturas da fachada norte do Bloco A

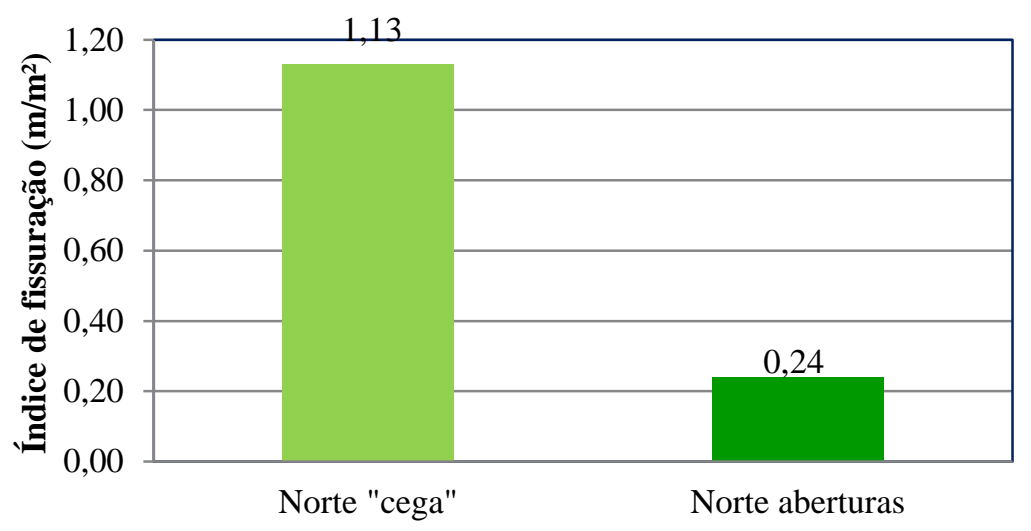

Figura 13 - Valores médios da temperatura nos detalhes arquitetônicos do Bloco B nos períodos seco e chuvoso (fachada norte)

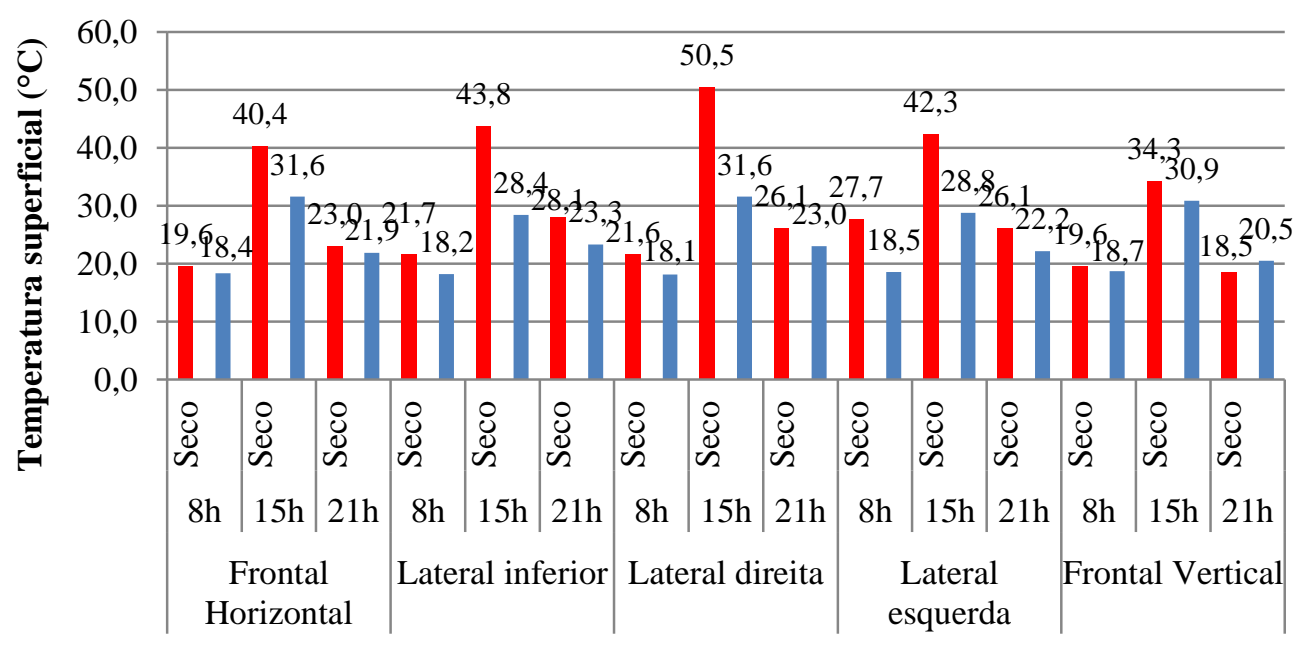

Localização - Fachada norte

66 Freitas, J. G. de; Carasek, H.; Cascudo, O. 
Figura 14 - Valores médios da temperatura superficial nos pontos sobre estrutura do Bloco A nos períodos seco e chuvoso

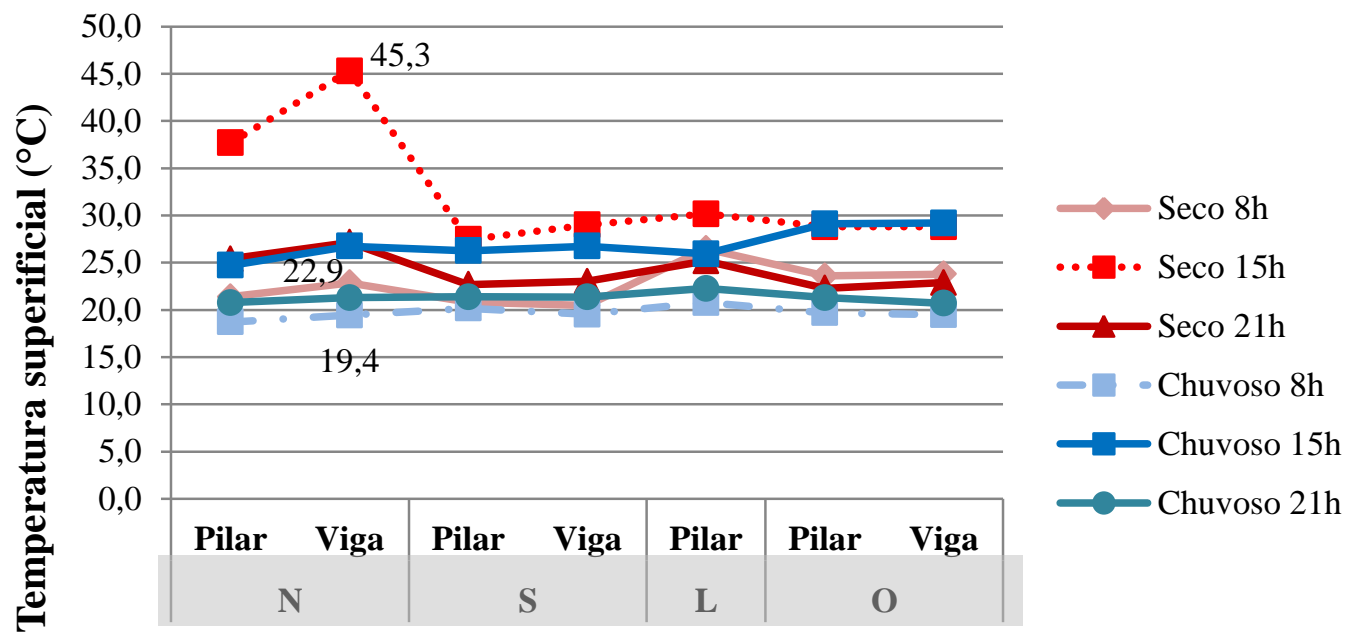

Orientação das fachadas

A Figura 15 apresenta a termografia obtida na fachada norte do Bloco $\mathrm{A}$ às $8 \mathrm{~h}$ da manhã. Nela, puderam-se detectar as maiores temperaturas (tonalidade laranja) em elementos que não estão em análise nesta pesquisa, como os materiais metálicos das janelas. A sombra formada pelo pilar ressaltado assim como o detalhe arquitetônico sobre a alvenaria também puderam ser detectados em tonalidades azuis, que representam as menores temperaturas superficiais. Neste caso, nenhuma manifestação patológica foi registrada pela termografia.

A Figura 16 apresenta a termografia obtida no mesmo local e período da imagem anterior, porém às 15h. Além dos elementos identificados anteriormente, a figura possibilitou a visualização de pontos de interesse, como manchas na platibanda apresentando maiores temperaturas (em torno de $45,5^{\circ} \mathrm{C}$ ). Na termografia, também foram identificadas algumas fissuras: uma acima da janela central (interface alvenaria/estrutura); uma formando $45^{\circ}$ com o vértice inferior da janela central; e outra acima da janela inferior (interface alvenaria/estrutura). Nesses pontos com fissuras, observou-se que as temperaturas eram um pouco inferiores (em torno de $39,5^{\circ} \mathrm{C}$ ) às observadas ao redor, ou seja, na alvenaria sem defeitos (em torno de $40,9^{\circ} \mathrm{C}$ ), resultando em uma diferença em torno de $1{ }^{\circ} \mathrm{C}$ menor. Outra informação detectada pela termografia foi a clara diferenciação dos pontos do revestimento sobre a estrutura (menor temperatura) e sobre a alvenaria (maior temperatura).
A Figura 17 apresenta a termografia obtida no mesmo local e período da imagem anterior, porém às $21 \mathrm{~h}$. Novamente, da mesma forma que às $8 \mathrm{~h}$, as manifestações patológicas (no caso, as fissuras) não puderam ser identificadas. Contudo, foram visualizados elementos construtivos da edificação, como os pontos do revestimento sobre a estrutura na parte superior (em torno de $24^{\circ} \mathrm{C}$ ).

Na Figura 18 está apresentada uma fotografia do mesmo trecho, na qual podem ser visualizadas as manifestações patológicas identificadas pela termografia na Figura 16. Por meio da análise das imagens termográficas, pode-se observar que o horário no período seco que melhor possibilitou a visualização de manifestações patológicas foi o da tarde (15h).

Na Figura 19 está apresentada a termografia da mesma área estudada, no entanto obtida no período chuvoso, às 15h. Apesar de se visualizarem maiores temperaturas nas áreas com manchas na platibanda, as isotérmicas durante o período chuvoso foram bastante similares, não permitindo a distinção de fissuras e tampouco dos diferentes materiais da base (alvenaria e estrutura de concreto). Salienta-se que esse comportamento se repetiu também nos outros dois horários (8h e 21h), nessa estação, mostrando que este não é um período adequado para identificação de manifestações patológicas por meio do termovisor. 
Figura 15 - Termografia da fachada norte do Bloco A às 8 h durante o período seco

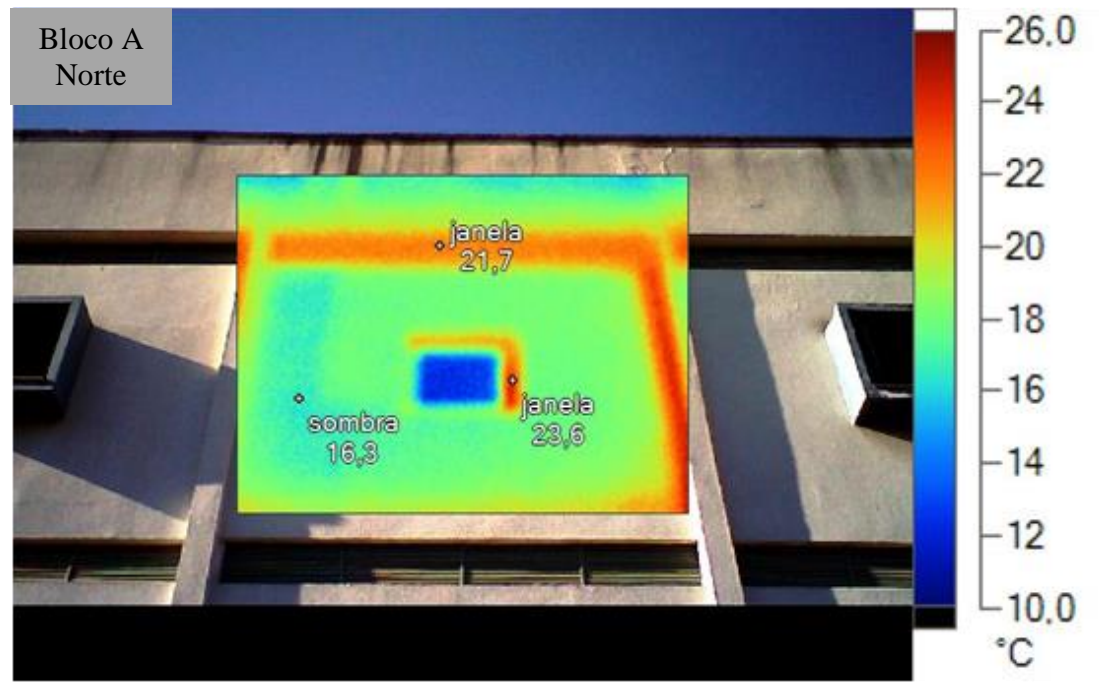

Figura 16 - Termografia da fachada norte do Bloco A às $15 \mathrm{~h}$ durante o período seco

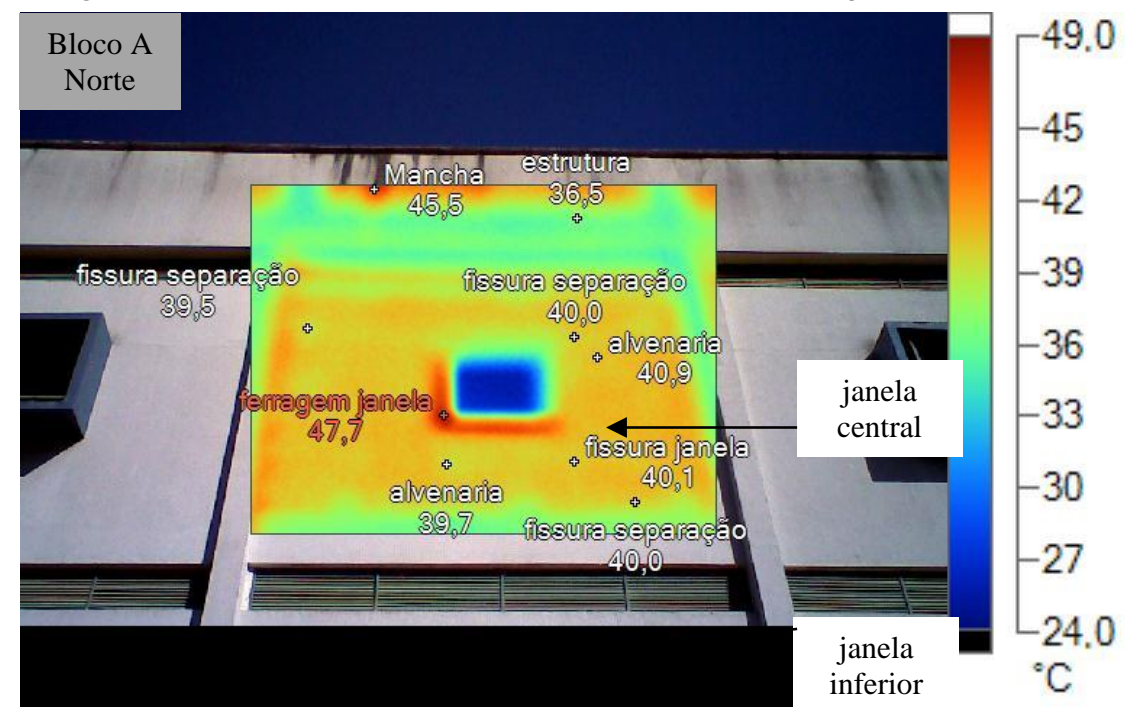

Figura 17 - Termografia da fachada norte do Bloco A às $21 \mathrm{~h}$ durante o período seco

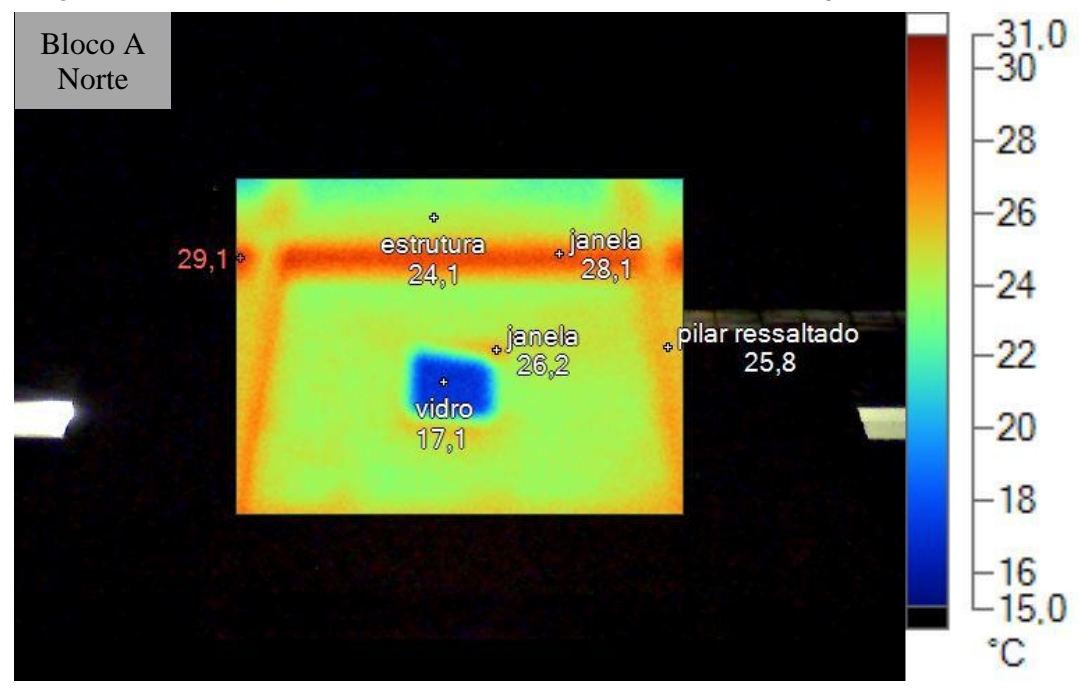

68 Freitas, J. G. de; Carasek, H.; Cascudo, O. 
Figura 18 - Fotografia da fachada norte do Bloco A



Nota: as fissuras horizontais foram delineadas com linhas azuis, pois a fotografia não permitiu resolução para sua visualização.

Figura 19 - Termografia da fachada norte do Bloco A às $15 \mathrm{~h}$ durante o período chuvoso

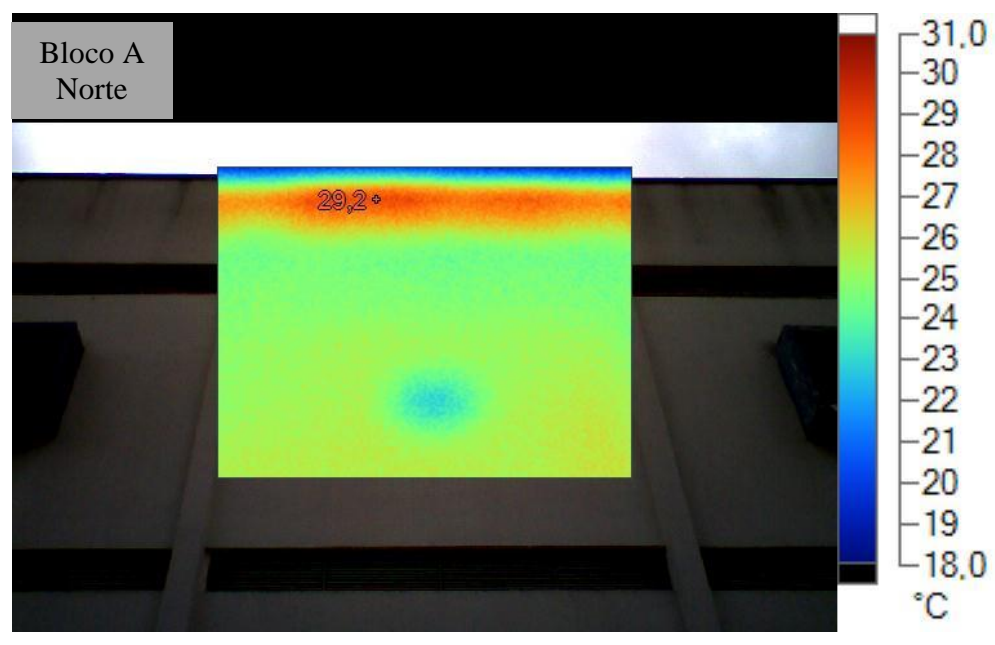

Na Figura 20 é apresentada uma termografia obtida na fachada norte do Bloco A às $15 \mathrm{~h}$ no período seco, especificamente onde foi focado o detalhe arquitetônico, e as manifestações patológicas visualizadas durante a etapa de inspeção. Por meio da análise e do tratamento da imagem no programa específico da câmera termográfica, novamente se identificaram defeitos, como as fissuras. Sobre essas regiões com fissuras, e nesse horário do dia (15h), verificou-se que a temperatura é em torno de $1{ }^{\circ} \mathrm{C}$ inferior em comparação aos pontos da alvenaria sem problemas visíveis. Ressalta-se que os valores encontrados por Cerdeira et al. (2011) foram similares, com variação de aproximadamente $1{ }^{\circ} \mathrm{C}$ entre os locais com e sem defeitos, em painéis de blocos cerâmicos revestidos com argamassa e placas de granito.
Além disso, observou-se parte do revestimento sobre alvenaria com temperatura inferior às áreas ao redor, também sobre alvenaria. Isso porque essa área é sombreada pelo detalhe arquitetônico nesse horário, não recebendo insolação direta. Verificouse também que o detalhe arquitetônico foi ressaltado na imagem, apresentando as maiores temperaturas captadas pela câmera termográfica (em torno de $54,3^{\circ} \mathrm{C}$ ), chegando a $58^{\circ} \mathrm{C}$ conforme escala de temperatura do lado direito da termografia. Ressalta-se que as medidas individuais de temperatura superficial realizadas na etapa anterior (obtidas pelo termômetro digital), chegaram a $54,3{ }^{\circ} \mathrm{C}$ em um dia de medição, o que se assemelha aos resultados obtidos na termografia. A Figura 21 apresenta a fotografia do mesmo trecho no mesmo horário. 
A respeito da fachada oeste do Bloco A, puderamse identificar pontos com fissuras que possuíam temperaturas inferiores (em torno de $36,3{ }^{\circ} \mathrm{C}$ ) em relação aos pontos do revestimento sem defeitos (em torno de $37,9^{\circ} \mathrm{C}$ ), conforme mostra a Figura 22a. Quanto às fissuras de interface entre alvenaria e estrutura, observou-se que a fissura estava abaixo da viga superior (estrutura da laje de cobertura), enquanto na viga inferior (estrutura da laje de piso do último pavimento) ela se manifestou na parte acima da viga. Já em relação ao pilar na região central, a fissura ocorreu do lado direito, conforme mostra a Figura 22b.

Figura 20 - Termografia da fachada norte do Bloco A às $15 \mathrm{~h}$ durante o período seco

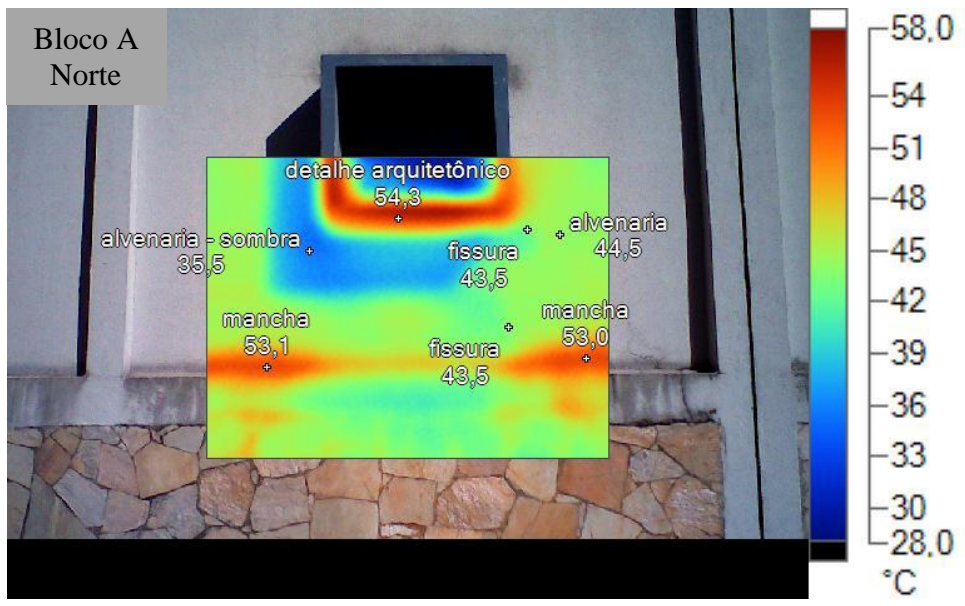

Figura 21 - Fotografia da mesma região da fachada mostrada na Figura 20

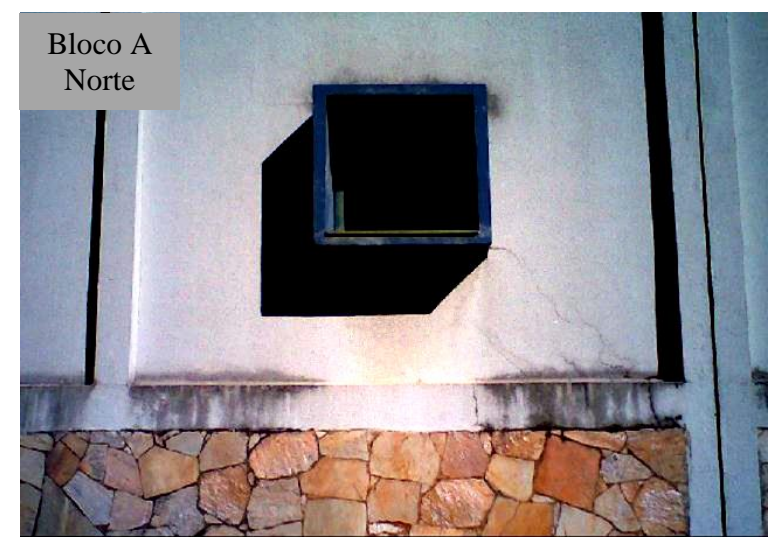

Figura 22 - Imagem termográfica da fachada oeste do Bloco A às $15 \mathrm{~h}$ (a) e o mapeamento das manifestações patológicas do mesmo local (b)

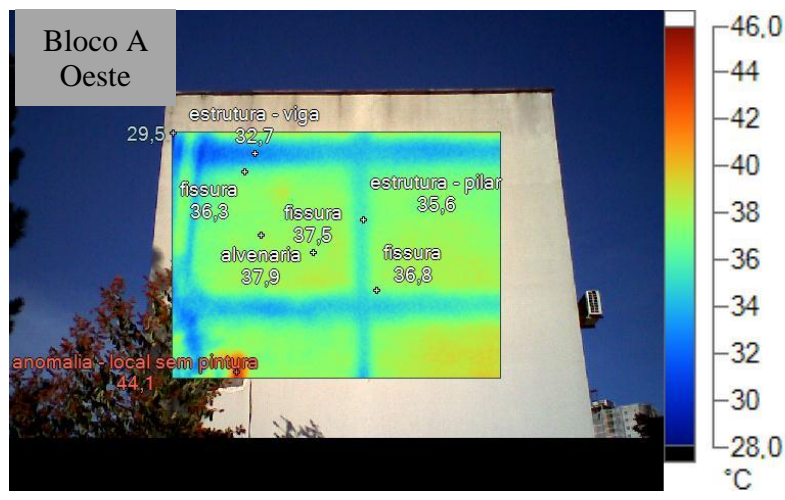

(a)

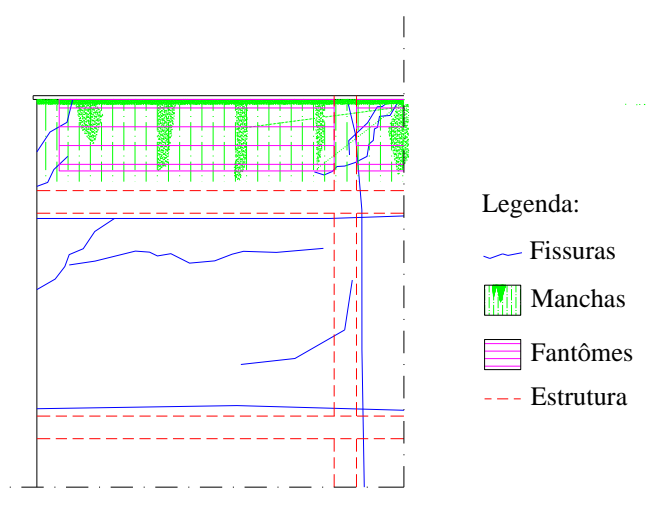

(b)

70 Freitas, J. G. de; Carasek, H.; Cascudo, O. 
Uma vez observada nas imagens termográficas a existência de uma variação de temperatura entre a região sem fissura e com fissura de aproximadamente $1{ }^{\circ} \mathrm{C}$, decidiu-se por fazer um intenso processamento das termografias visando comprovar essa variação. Foram analisadas então 120 imagens do Bloco A e aferidos nessas imagens 362 pontos (com e sem defeito em regiões de alvenaria bem próximas), compreendendo as fachadas norte e sul, que possuíam o maior número de termografias. A Tabela 1 apresenta a compilação dos resultados dessa análise, após a retirada de espúrios (por comparação com valores extremos de uma distribuição normal, considerando um nível de significância de 5\%).

Na Tabela 1 observa-se que as médias das diferenças de temperatura encontradas nas duas fachadas são praticamente iguais (aproximadamente $1{ }^{\circ} \mathrm{C}$ ). Além disso, as medianas são exatamente iguais $\left(0,8^{\circ} \mathrm{C}\right)$, o que confirma de forma estatística a tendência anteriormente observada de existir uma pequena diferença de temperatura entre pontos sem e com fissuras na alvenaria, apesar do alto coeficiente de variação, principalmente na fachada norte. Essa diferença de temperatura aproximada de $1{ }^{\circ} \mathrm{C}$ é explicada pela desigual transferência de calor por condução através da parede, nos pontos com e sem fissuras, uma vez que o ar atua como camada de isolamento e dificulta a transferência de energia térmica através da parede.

Observou-se também uma leve tendência de haver maiores diferenças de temperatura (entre as regiões com e sem fissuras) nas fachadas mais aquecidas, assim como se verificou maior dispersão dessas variações medidas para as fachadas mais quentes. A Figura 23 ilustra esse comportamento.

\section{Conclusões}

O mapeamento das manifestações patológicas possibilitou o cálculo do índice de fissuração para as quatro orientações dos edifícios em estudo. Relacionando-o às medições de temperatura superficial, verificaram-se altos níveis de fissuração para a fachada norte, onde ocorreram os maiores ciclos de temperatura. Esse fato é explicado pela insolação recebida por esta fachada, durante quase todo o dia, nos dois períodos de medição (seco e chuvoso). Ao contrário, verificaram-se níveis de fissuração mais baixos, bem como de ciclos de temperatura, na fachada sul.

Tabela 1 - Diferença de temperatura em pontos sem defeitos e em locais com fissuras, nos revestimentos sobre a alvenaria das fachadas Norte e Sul do Bloco A

\begin{tabular}{l|c|c}
\hline & Norte & Sul \\
\hline Tamanho da amostra $(\mathrm{n})$ & 111 & 70 \\
Média da diferença de temperatura $\left({ }^{\mathbf{0}} \mathrm{C}\right)$ & $\mathbf{0 , 9 9}$ & $\mathbf{0 , 9 7}$ \\
Desvio padrão $\left({ }^{\circ} \mathrm{C}\right)$ & 1,06 & 0,63 \\
Coeficiente de variação $(\%)$ & 107 & 65 \\
Mediana $\left({ }^{\circ} \mathrm{C}\right)$ & 0,80 & 0,80 \\
Espúrios & 3 valores & 1 valor \\
\hline
\end{tabular}

Figura 23 - Relação entre a temperatura da parede (em áreas sem fissura) e a diferença de temperatura observada entre os pontos sem fissura e com fissura

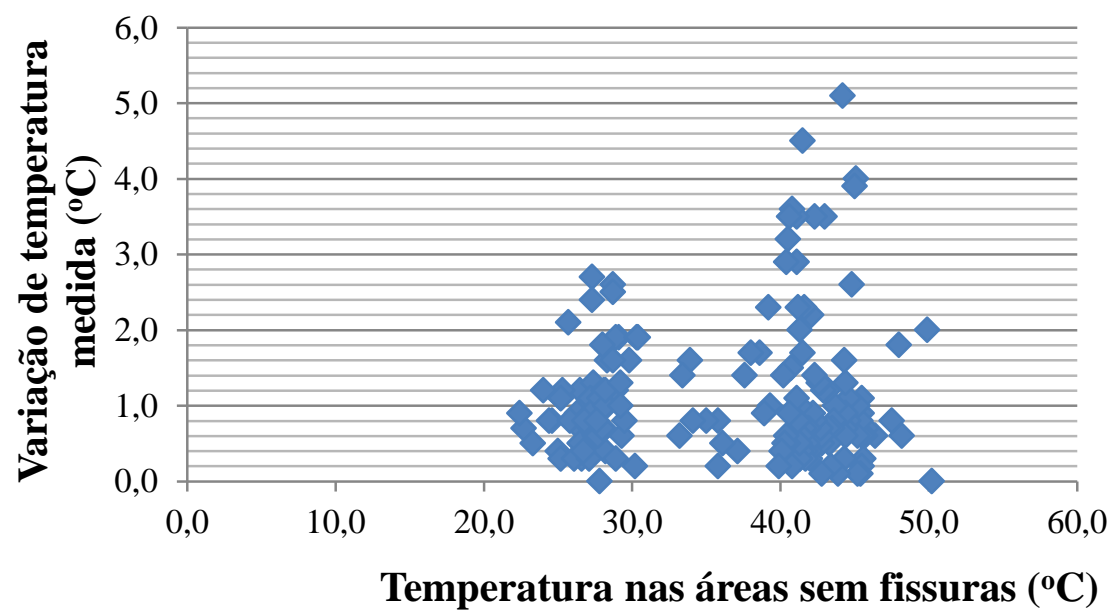


As fachadas voltadas para leste e oeste de ambos os blocos apresentaram níveis de temperatura superficiais quase sempre semelhantes. Os maiores níveis de fissuração foram medidos nestas orientações. Contudo, deve-se ressaltar que são "fachadas cegas", possuindo comportamento diferenciado das demais. A predominância do tipo de fissuração é relacionada à movimentação térmica e, provavelmente, à deficiência ou mesmo ausência dos conectores de ancoragem entre a alvenaria e a estrutura.

Os altos níveis de temperatura atingidos nos detalhes arquitetônicos são explicados pela insolação direta (sem nebulosidade) recebida pela fachada norte durante todo o dia no período seco e a cor da tinta utilizada na pintura desses elementos, que é o azul-escuro, representando maior absortividade. $\mathrm{O}$ maior valor médio de temperatura superficial ocorrido atingiu 50,5 ${ }^{\circ} \mathrm{C}$. Contudo, ressalta-se que a temperatura máxima chegou a $65,5^{\circ} \mathrm{C}$ nos valores individuais de medição, o que compromete a utilização desse tipo de detalhe arquitetônico em edifícios, notadamente com a coloração escura.

A utilização da termografia para o diagnóstico de manifestações patológicas em revestimentos de argamassa de fachadas nos edifícios em estudo permitiu as conclusões a seguir. As medições no horário da tarde (15h) e na estação climática seca possibilitaram a identificação de fissuras, traduzindo, assim, as condições mais favoráveis para as inspeções com o termovisor. Houve, portanto, uma boa correlação do mapeamento realizado, assim como das medições de temperatura feitas nas superfícies das fachadas, com as imagens termográficas produzidas. Contudo, nem todas as manifestações patológicas mapeadas foram visualizadas nas imagens termográficas. Utilizando-se o programa computacional da câmera termográfica, puderamse identificar os pontos com manifestações patológicas não visualizados por meio da escala de cores da termografia. Isso porque o recurso possibilita a sobreposição das imagens térmica e digital, bem como a aferição da temperatura superficial em pontos de interesse de análise. Dessa forma, verificou-se que o revestimento fissurado possui temperatura cerca de $1{ }^{\circ} \mathrm{C}$ inferior ao revestimento sem defeitos.

Pelos resultados deste trabalho e experiência adquirida na pesquisa, pode-se afirmar que a termografia infravermelha se apresenta como uma ferramenta de elevado potencial a serviço das atividades de inspeção, avaliação e diagnóstico de problemas em revestimentos, em especial nas fachadas de edifícios. A possibilidade de melhor compreensão dos fenômenos e eventos incidentes nos paramentos, associados às questões térmicas e higroscópicas, faz dessa técnica um instrumento agregador no campo dos novos projetos e da especificação de materiais e componentes voltados aos sistemas de vedação em alvenaria e de revestimento. Um caminho promissor, portanto, se apresenta como contribuição ao desempenho sistêmico dos revestimentos de fachada em edificações.

\section{Referências}

ALBATICI, R.; TONELLI, A. M. Infrared Thermovision Technique for the Assessment of Thermal Transmittance Value of Opaque Building Elements on Site. Energy and Buildings, v. 42, n. 11, p. 2177-2183, 2010.

ANTUNES, G. R. Estudo de Manifestações Patológicas em Revestimento de Fachada em Brasília: sistematização da incidência de casos. Brasília, 2010. 166 f. Dissertação (Mestrado em Engenharia Civil) - Departamento de Engenharia Civil e Ambiental, Universidade de Brasília, Brasília, 2010.

\section{AMERICAN SOCIETY FOR TESTING AND MATERIALS. ASTM C 1060-11a: standard} practice for thermographic inspection of insulation installations in envelope cavities of frame buildings. In: ANNUAL BOOK OF STANDARDS, Philadelphia, 2011. v. 04.06. ASSOCIAÇÃO BRASILEIRA DE NORMAS TÉCNICAS. NBR 15220-2: desempenho térmico de edificações: parte 2 : métodos de cálculo da transmitância térmica, da capacidade térmica, do atraso térmico e do fator solar de elementos e componentes de edificações. Rio de Janeiro, 2005.

BARREIRA, E.; FREITAS, V. P. Evaluation of Building Materials Using Infrared Thermography. Construction and Building Materials, v. 21, n. 1, p. 218-224, 2007.

BARREIRA, E.; FREITAS, V. P. Importance of Thermography in the Study of ETICS Finishing Coatings Degradation Due to Algae and Mildew Growth. In: DBMC INTERNATIONAL CONFERENCE ON DURABILITY OF BUILDING MATERIALS AND COMPONENTS, Lyon, 10., Proceedings... Lyon, 2005.

CERDEIRA, F. et al. Applicability of Infrared Thermography to the Study of the Behaviour of Stone Panels as Building Envelopes. Energy and Buildings, v. 43, n. 8. p. 1845-1851, ago. 2011.

CORTIZO, E. C.; BARBOSA, M. P.; SOUZA, L. A. C. Estado da Arte da Termografia. Ambiente Construído e Patrimônio Sustentável, v. 2, n. 2, p. 158-193, 2011. 
CORTIZO, E. C. Avaliação da Técnica de Termografia Infravermelha Para Identificação de Estruturas Ocultas e Diagnóstico de Anomalias em Edificações: ênfase em edificações do patrimônio histórico. Belo Horizonte, 2007. 177 f. Tese (Doutorado em Engenharia Mecânica) Escola de Engenharia, Universidade Federal de Minas Gerais, Belo Horizonte, 2007.

DACTU, S. et al. Improvement of Building Wall Surface Temperature Measurements by Infrared Thermography. Infrared Physics and

Technology, v. 46, p. 451-467, 2005.

FERNANDES, A. M. C. P. Arquitetura e

Sombreamento: parâmetros para a região climática de Goiânia. Goiânia, 2007. 119 f. Dissertação (Mestrado em Arquitetura) Faculdade de Arquitetura, Universidade Católica de Goiás, Goiânia, 2007.

FREITAS, J. G. A influência das Condições Climáticas na Durabilidade dos Revestimentos de Fachada: estudo de caso na cidade de Goiânia GO. Goiânia, 2012. 196 f. Dissertação (Mestrado em Engenharia Civil) - Escola de Engenharia Civil, Universidade Federal de Goiás, Goiânia, 2012.

GASPAR, P.; BRITO, J. Mapping Defect Sensitivity in External Mortar Renders.

Construction and Building Materials, v. 19, n. 8, p. 571-578, 2005.

GUIMARÃES, L. E. et al. Acompanhamento das Variações das Temperaturas Superficiais dos Principais Materiais Utilizados em Fachadas. In: ENCONTRO SOBRE PESQUISA DE MATERIAIS DE CONSTRUÇÃO, 2., Goiânia, 2002. Anais... Goiânia, 2002.
GRINZATO, E. et al. Infrared Thermography For Moisture Detection: a laboratory study and in-situ test. Materials Evaluation, p. 97-104, jan. 2011.

LERMA, J. L.; CABRELLES, M.; PORTALÉS, C. Multitemporal Thermal analysis to Detect Moisture on a Building Façade. Construction and Building Materials, v. 25, n. 5, p. 2190-2197, 2011.

LIMA, R. C. F.; MAGNANI, F. S.; NUNES, R. Detecção de Falhas em Monumentos Históricos de Olinda Através de Imagens por Infravermelho.

Revista Brasileira de Arqueometria

Restauração Conservação, v. 1, 2006.

MARIO, M. Uso da Termografia Como Ferramenta Não Destrutiva Para Avaliação de Manifestações Patológicas Ocultas. Porto Alegre, 2011. 68 f. Monografia (Graduação em Engenharia Civil) - Departamento de Engenharia Civil, Universidade Federal do Rio Grande do Sul, Porto Alegre, 2011.

MOROPOULOU, A.; AVDELIDIS, M. K.; KOUI, M. Compatibility Assessment of Building Materials Using Infrared Thermography. In: WORLD CONFERENCE ON NONDESTRUCTIVE TESTING, 15., Rome, 2000. Proceedings... Rome, 2000.

MENDONÇA, L. V. Termografia Por Infravermelhos: inspecção de betão. Engenharia e Vida, v. 1, n. 16, p. 53-57, 2005.

Juliana Gomes de Freitas

Escola de Engenharia Civil | Universidade Federal de Goiás | Av. Universitária, n. 1488, Quadra 86, Lt. Área, Bloco A, Sala 12, Setor | Universitário, Goiânia - GO - Brasil | CEP 74605-220 | Tel.: (62) 3209-6262 | E-mail: julianagfreitas@gmail.com

Helena Carasek

Escola de Engenharia Civil | Universidade Federal de Goiás | Email: hcarasek@gmail.com

Oswaldo Cascudo

Escola de Engenharia Civil | Universidade Federal de Goiás | Email: ocascudo@gmail.com

Revista Ambiente Construído

Associação Nacional de Tecnologia do Ambiente Construído

Av. Osvaldo Aranha, $99-3^{\circ}$ andar, Centro

Porto Alegre - RS - Brasil CEP 90035-190

Telefone: +55 (51) 3308-4084

Fax: +55 (51) 3308-4054

www.seer.ufrgs.br/ambienteconstruido

E-mail: ambienteconstruido@ufrgs.br 